\title{
correspondence
}

\section{Jobs: the need to reach an ideal steady state}

SIR,-The problem of short-term contract workers is a serious one but it is also very complex and one should beware of facile solutions which can have even more disastrous long term repercussions.

To illustrate the problem one has to look at the ideal steady state. In the biomedical sciences we estimate that there ate about 5,000 tenured academic and research posts in United Kingdom

Universities and research institutes. There is probably about the same number in the physical sciences. Since each tenured post is occupied for about 35 years the average turnover rate, assuming no wastage, should be about $2.8 \%$ per annum. With a uniform age distribution, we could expect 130 vacancies every year in the biomedical sciences simply for renewal. It would mean that we could have a total of 400 people in three year postdoctoral fellowships with excellent chances of their being placed in tenured posts at completion.

The problem is that we are very far from this situation. In 1976, only $20 \%$ of the science posts in British universities had holders aged 50 and above, which means that for the next 15 years the retirement rate is going to be about $1 \%$ and we can only expect positions to appear about $\frac{1}{3}$ of that expected from the ideal steady state. Thus the biomedical sciences will only have about 30 to 40 vacancies a year which not only accords more with what we know to be the case, but also tells us that this will be with us to very near the end of the century. The reasons are obvious; this generation is now paying the price for the rapid change in the rate of expansion in the late fifties and sixties; the people they are replacing were appointed before that when the system was much smaller. It is also easy to see that if the step at the below 40 age group is followed by a trough, the long term consequences could be disastrous.

The only solution is to aim to get to the ideal steady state position now. Tenured posts must be offered in universities at the average turnover rate, but in order to do this the system will have to undergo an absolute expansion. Naturally this bulge should not enter into the calculation of the turnover rate, but should be seen only as a borrowing against future vacancies. It seems to me that, in the main, this has to be done largely by government intervention as part of a deliberately planned policy. Nevertheless, there are contributions which might be made by private foundations and possibly by research councils. The best they could do would be to create senior research positions in universities for people already holding university posts. These would all be ad hominem appointments so that the subject areas and the candidates are selected by these organisations, and the posts are not simply given away with no control. However, the position vacated by such an appointment can now become available to the university for a new entrant. In essence, in this scheme, the outside organisation is only temporarily committing itself to a university for the length of tenure of the post, perhaps 15 years; for new tenured entrants, the commitment is for 40 years and only the universities can do that.

From this analysis it can be seen that temporary posts do not help, except as offering some small buffering capacity.

They can only be created and used effectively against future vacancies, and unless accompanied by other actions they can only worsen the situation. A prolonged postdoctoral period can be seen as a mechanism which gives the occupants several additional opportunities to apply for permanent posts as they arise annually. This does not help as long as the input further back in the system provides excessive competition, and the difficulties are further compounded by the universities choosing younger candidates for lectureships because they are cheaper than the man with several years experience. We have also to tackle the question of the number of people doing $\mathrm{PhD}$ degrees, and this raises a whole new set of problems. What is a PhD degree for? If it is seen as the first step towards a research or academic career, and this is the expectation of people doing it, then we are producing too many, and the numbers should be cut.

Universities would strongly oppose that step, because $\mathrm{PhD}$ students provide a cheap source of research labour in many university science departments. We have to look at postgraduate education and training as a matter of urgency; it is clearly impossible and undersirable for every university to have a graduate school in every subject, since that puts demands on resources that cannot be met.

The question of the short-term workers is only the tip of the iceberg and the central problems are deepseated and long term. In some way, everybody involved needs to be got together to find a national solution; and unless this is done soon and in a concerted manner I, for one, am very nervous about the long term future for British science and higher education.

SYDNEY BRENNER

MRC Laboratory of Molecular Biology, Hills Road, Cambridge.

\section{Little danger from radon}

SIR,--Recently, Nature reported (30 November 1978, page 431) the work of Berkeley scientists who have expressed concern that reduced ventilation rates may increase the hazard from the inhalation of the short-lived daughters of ${ }^{222} \mathrm{Rn}$. This problem has been under consideration by the National Radiological Protection Board in recent years and we think that the conclusions reached by the workers at Berkeley should be approached with caution.

They based their case on extrapolation from uranium miners' medical data. For uranium miners, W. Jacobi (Proceedings of NEA Specialist Meeting, Elliot Lake, Canada, OECD, Paris pp. 33-38; 1977) has estimated 200 excess lung cancer deaths among a population with a cumulative exposure of $10^{6}$ Working Level Months. (The Working Level Month
Table 1 Lung cancer incidence predicted due to environmental radon daughter exposure

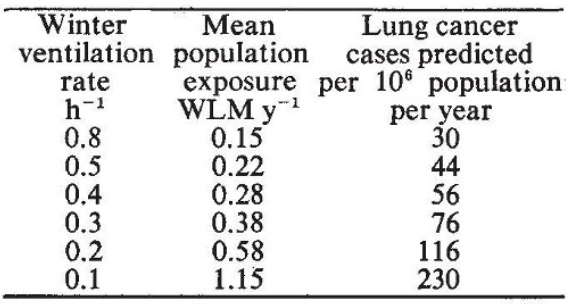

(WLM) is 170 hours exposure at 1 Working Level (WL); the Working Level is a measure of the concentration of the potential alpha energy in air from any combination of the short-lived daughters of radon. $1 \mathrm{WL}=1.3 \times 10^{8} \mathrm{MeV} \mathrm{m}^{-3}$ ). A recent survey (Cliff, K. D., Phys. Med. Biol. 23, 696-711; 1978) estimated that the average population exposure rate domestically to radon daughters for Great Britain is about 0.15 WLM per year.

From the above figures it is possible to deduce, for the female population of Great Britain (assuming a 20 year latency period) that inhalation of radon daughters has caused more bronchus and lung cancer deaths up to the age of 40 than actually occur from every single cause, according to mortality statistics. This result shows the danger of applying a risk estimate derived from a special group to other groups of the population. Even if allowance were made for more rapid room ventilation in the days of open fires, we would still deduce that lung cancer incidence among women under 40 was entirely attributable to radon, and that smoking made little contributionan untenable conclusion.

Is a WLM to a working miner the same, from a comparative dosimetry point of view, as that to a member of the general population? Studies show that, to within a factor 2, there is no difference in the deposition of radon daughters in the lung. In the absence of any other data, apart from that for miners, on which to base a risk estimate for the general population we may use Jacobi's figure to consider the implications of a general reduction in ventilation rates during winter. We assume a mean ventilation rate in summer ( 5 months) of two room changes per hour and that energy conservation efforts will not alter this rate. Table 1 shows the predicted incidence of lung cancer in the population (male and female) of Great Britain as the mean winter ( 7 months) ventilation rate is reduced. The current total lung cancer incidence in Great Britain is about 650 per $10^{8}$ population per year.

It cannot be stressed too strongly that such calculations as given in Table 1 should be regarded as speculative and represent an absolute upper limit to possible lung cancer incidence attributable to environmental radon daughter concentrations.

\section{K. D. ClifF}

B. L. Davies J. A. Reissland

National Radiological Protection

Board, Harwell, UK 